\title{
Characterization of a novel cysteine protease in Trichinella spiralis and its role in larval intrusion, development and fecundity
}

\author{
Yuan Yuan Hu, Ru Zhang, Shu Wei Yan, Wen Wen Yue, Jia Hang Zhang, Ruo Dan Liu, Shao Rong Long, \\ Jing Cui* (D) and Zhong Quan Wang*
}

\begin{abstract}
The aim of this study was to investigate the biological properties of a novel gut-specific cysteine protease in Trichinella spiralis (TsGSCP) and its role in larval intrusion, development and fecundity. TsGSCP has a functional C1 peptidase domain; C1 peptidase belongs to cathepsin B family. The TsGSCP gene cloned and expressed in Escherichia coli BL21 showed intensive immunogenicity. GPCR and Western blotting revealed that TsGSCP mRNA and protein were expressed at various T. spiralis stages, but their expression levels in intestinal infectious larvae (IIL) were clearly higher than those in muscle larvae (ML), adult worms (AWs) and new-born larvae (NBL). Indirect immunofluorescence (IIF) analysis showed that TsGSCP was primarily located at the outer cuticle and the intrauterine embryos of this parasite. rTsGSCP showed the ability to specifically bind with IECs, and the binding site is within the IEC cytoplasm. rTsGSCP accelerated larval intrusion into host intestinal epithelial cells (IECs), whereas anti-rTsGSCP antibodies suppressed larval intrusion; the acceleration and suppression was induced by rTsGSCP and anti-rTsGSCP antibodies, respectively, in a dose-dependent manner. When ML were transfected with TsGSCP-specific dsRNA, TsGSCP expression and enzymatic activity were reduced by 46.82 and $37.39 \%$, respectively, and the capacity of the larvae to intrude into IECs was also obviously impeded. Intestinal AW burden and adult female length and fecundity were significantly decreased in the group of mice infected with dsRNA-transfected ML compared to the control dsRNA and PBS groups. The results showed that TsGSCP plays a principal role in gut intrusion, worm development and fecundity in the T. spiralis lifecycle and might be a candidate target for vaccine development against Trichinella intrusion and infection.
\end{abstract}

Keywords: Trichinella spiralis, cysteine protease, intrusion, fecundity, dsRNA

\section{Introduction}

Trichinellosis is a worldwide zoonotic parasitic disease that is principally caused by the consumption of raw or undercooked meat containing Trichinella muscle larvae (ML) [1]. Mammals, rodents, amphibians, reptiles and birds are hosts of Trichinella [2]. Human Trichinella infection mainly results from eating infected pork in developing countries [3-5]. Twelve outbreaks of human

*Correspondence: cuij@zzu.edu.cn; wangzq2015@126.com Department of Parasitology, Medical College, Zhengzhou University, Zhengzhou 450052, China trichinellosis due to infected pork or pork products were documented in China in 2004-2009 [6]. Because pork from domestic pigs is consumed in high quantities around the world, porcine Trichinella infection is a major risk to public health and meat safety [7]. Hence, it is necessary to develop preventive vaccines to interdict the transmission of swine Trichinella infection and eliminate Trichinella infectious larvae in animals consumed as food [8].

Following ingestion, T. spiralis ML encapsulated in host skeletal muscles are released from collagen capsules in the stomach by the action of digestive enzymes original author(s) and the source, provide a link to the Creative Commons licence, and indicate if changes were made. The images or other third party material in this article are included in the article's Creative Commons licence, unless indicated otherwise in a credit line to the material. If material is not included in the article's Creative Commons licence and your intended use is not permitted by statutory regulation or exceeds the permitted use, you will need to obtain permission directly from the copyright holder. To view a copy of this licence, visit http://creativecommons.org/licenses/by/4.0/. The Creative Commons Public Domain Dedication waiver (http://creativeco mmons.org/publicdomain/zero/1.0/) applies to the data made available in this article, unless otherwise stated in a credit line to the data. 
and activated into intestinal infective L1 larvae (IIL1) after exposure to intestinal contents or bile $0.9 \mathrm{~h}$ postinfection (hpi) [9, 10]. IIL1 recognize, invade and migrate within intestinal epithelium cells (IECs) and establish an intramulticellular niche in the intestinal columnar epithelium, where at 10 hpi IIL1 undergo their first moulting and develop into IIL2 and then moult three times before becoming adult worms (AWs) 10-31 hpi. After female and male AWs mate, pregnant adult females generate the next generation of new-born larvae (NBL), and these NBL pass into the blood circulation, invade skeletal muscles and are encapsulated to complete the lifecycle [11]. Invasion of IECs by IIL1 is the most important step in T. spiralis infection and parasitism within the host intestine. The intestinal epithelium is the first natural barrier against $T$. spiralis invasion and the main interaction site of the nematode and host [12, 13], but the mechanism of IIL1 penetration into IECs has not been fully elucidated [14, 15]. Identification and characterization of IIL1 invasionrelated protein molecules in T. spiralis will contribute to an understanding of the IEC invasion mechanism and will be valuable to exploit preventive vaccines that block Trichinella invasion [16, 17].

Previous studies revealed that when they were cocultivated with an IEC monolayer, IIL invaded the monolayer and produced additional cysteine proteases that entered the IECs $[18,19]$. Cysteine proteases have been identified in somatic soluble and excretory/secretory (ES) proteins of T. spiralis [20]. These cysteine proteases might promote IIL1 penetration of IECs in the process of Trichinella infection [21-23]. Our previous studies showed that several $T$. spiralis cysteine proteases participate in IIL1 invasion, and immune serum against recombinant cysteine proteases or RNAi partially suppressed IIL1 intrusion [24, 25]. Recombinant protein vaccination of mice led to only partial immune protection against $T$. spiralis challenge [26, 27]. These results suggested that other cysteine proteases participate in larval invasion of IECs. Therefore, it is necessary to characterize other cysteine proteases and evaluate their roles in larval intrusion, development and fecundity in the lifecycle of T. spiralis.

Cysteine proteases constitute a superfamily of widespread proteolytic enzymes in parasitic organisms and play a primary role in the lifecycle of parasites, including worm intrusion, migration and development, exsheathing, digestion and degradation of host proteins, and immune evasion [28-30]. The cysteine protease contains cathepsin $\mathrm{B}, \mathrm{C}, \mathrm{F}, \mathrm{H}, \mathrm{K}, \mathrm{L}, \mathrm{O}, \mathrm{S}, \mathrm{V}, \mathrm{W}$ and $\mathrm{X}$ [31]. Cathepsin $\mathrm{B}$ is a member of the papain-like cysteine protease family from clan CA, exhibits conspicuous hydrolytic activity and might be secreted into the intercellular matrix and bound to the cellular membrane.
In this study, a novel gut-specific cysteine protease of T. spiralis (TsGSCP, GenBank: XP_003377240.1) was obtained from the T. spiralis draft genome [32]. TsGSCP has a functional $\mathrm{C} 1$ peptidase (cathepsin $\mathrm{B}$ family) domain. The aim of this study was to assess the biological properties of TsGSCP and its role in T. spiralis invasion of host intestinal mucosa.

\section{Materials and methods}

\section{Experimental animals, Trichinella and cells}

Four-week-old female KM mice were purchased from the Henan Experimental Animal Center. The Trichinella spiralis isolate (ISS534) used in this experiment was obtained from a domestic pig in Nanyang, Henan Province [33]. IECs were isolated from the small intestine of normal BALB/c mice [9]. The negative control cells were C2C12 myoblasts obtained from mouse muscles [34]. The bacterial strain used in the experiment was Escherichia coli BL21.

\section{Collection of worms at various stages and antigen preparation}

The carcasses of mice infected with $T$. spiralis were artificially digested 40 days post-infection (dpi) to obtain ML [35]. The IIL and AWs were collected from the small intestine at $6 \mathrm{hpi}, 3 \mathrm{dpi}$ and $6 \mathrm{dpi}[36,37]$. NBL were acquired from 6-day-old females after culturing for $24 \mathrm{~h}$ [38]. The soluble somatic worm antigens in various T. spiralis stages (ML, IIL, AW and NBL) and IIL ES antigens were prepared as previously described $[39,40]$.

\section{Bioinformatics analysis and evolutionary tree construction} The full-length cDNA sequence of the TsGSCP gene was obtained from NCBI. Bioinformatics analysis software (TargetP, TMHMM, SMART, ProtParam, Swiss-Model, ProtScale, PSIPred and SignalP) was used to analyse and predict its physicochemical properties, such as signal peptide, subcellular localization, tertiary structure of TsGSCP and functional sites [17]. The amino acid sequences of TsGSCP were compared with the cysteine protease from other organisms with BioEdit software [30]. The GenBank accession numbers of the cysteine proteases from other organism are as follows: T. nelsoni (KRX27624.1), Trichinella sp. T8 (KRZ92878.1), T. nativa (OUC48635.1), T. patagoniensis (KRY19675.1), Trichinella sp. T6 (KRX85497.1), T. papuae (KRZ80814.1), T. zimbabwensis (KRZ19202.1), T. pseudospiralis (KRZ16984.1), Trichuris suis (KFD71793.1), Brugia malayi (XP_001898194.1), Caenorhabditis elegans (NP_506002.2), Schistosoma mansoni (XP_018651608.1), Echinococcus granulosus (XP_024356149.1), Mus musculus (NP_031824.1) and Homo sapiens (NP_001899.1). The phylogenetic tree analysis of TsGSCP was performed 
with MEGA 7.0 using the neighbour-joining (NJ) method [41].

\section{Cloning and expression of rTsGSCP}

According to the coding sequence (CDS) of TsGSCP after the signal peptide sequence was removed, TsGSCP-specific primers containing the BamHI and PstI restriction sites (bold) were designed. The primer sequences were $5^{\prime}$-GCGGATCCGCCTACTACGAAGAGACATA- $3^{\prime}$ and 5'-CGCTGCAGTTATATTCTTGCCATTCCAGCTA- ${ }^{\prime}$. cDNA was extracted from the ML and used as a template to amplify the TsGSCP gene. The recombinant expression plasmid pMAL-c2x/TsGSCP was constructed and introduced into Escherichia coli BL21 (Novagen, USA) $[41,42]$. $r$ TsGSCP was induced with $1 \mathrm{mM}$ isopropyl $\beta$-D1-thiogalactopyranoside (IPTG) at $25^{\circ} \mathrm{C}$ for $6 \mathrm{~h}$ and purified by affinity chromatography using amylose resin (New England Bio-labs, USA).

\section{Preparation of immune serum and an anti-rTsGSCP IgG titre assay}

Ten mice were subcutaneously immunized using $20 \mu \mathrm{g}$ of rTsGSCP emulsified with complete Freund's adjuvant. Booster immunization was administered three times with $20 \mu \mathrm{g}$ of rTsGSCP emulsified with incomplete Freund's adjuvant with 2-week intervals [43, 44]. Tail blood from immunized mice was collected two weeks after the final immunization, and anti-rTsGSCP serum was isolated. Anti-rTsGSCP IgG titres were measured using rTsGSCP-ELISA as previously described [45]. In brief, the plate was coated with $1 \mu \mathrm{g} / \mathrm{mL}$ rTsGSCP at $4{ }^{\circ} \mathrm{C}$ and incubated overnight. After washing with PBST, the plate was blocked with $5 \%$ skim milk and incubated with serial dilutions of immune serum for $2 \mathrm{~h}$ at $37^{\circ} \mathrm{C}$, followed by incubation with HRP-conjugated anti-mouse IgG for $1 \mathrm{~h}$ at $37^{\circ} \mathrm{C}$. Colour was developed with OPD (SigmaAldrich, USA) plus $\mathrm{H}_{2} \mathrm{O}_{2}$, and the reaction was terminated with $2 \mathrm{M} \mathrm{H}_{2} \mathrm{SO}_{4}$. The absorbance at $492 \mathrm{~nm}$ was measured with a microplate reader (Tecan Schweiz AG, Switzerland) [46, 47].

\section{Western blot analysis}

Soluble crude antigens of $T$. spiralis obtained at various stages, IIL ES antigens and purified rTsGSCP were separated by $10 \%$ SDS-PAGE. The proteins were transferred onto nitrocellulose (NC) membranes (Millipore, USA) in semidry transfer cells (Bio-Rad, USA) [37, 48]. The membrane was blocked with $5 \%$ skim milk in Tris-buffered saline containing $0.05 \%$ Tween (TBST) at $37{ }^{\circ} \mathrm{C}$ for $2 \mathrm{~h}$ and cut into strips. The strips were probed by various sera (1:200; anti-rTsGSCP serum, infection serum and preimmune serum) at $37{ }^{\circ} \mathrm{C}$ for $2 \mathrm{~h}$. Following washes with TBST, the strips were incubated at $37{ }^{\circ} \mathrm{C}$ for $1 \mathrm{~h}$ with HRP-conjugated anti-mouse IgG (1:10 000; Southern Biotech, USA). After being rewashed, the strips were coloured using 3,3'-diaminobenzidine tetrahydrochloride (DAB; Sigma-Aldrich, USA) or reagent from an enhanced chemiluminescent kit (CWBIO, Beijing, China) [49].

\section{qPCR assay}

Total RNA from diverse T. spiralis phases (ML, IIL, 3- and 6-day AW, and NBL) was isolated using TRIzol reagent (Invitrogen, USA). TsGSCP mRNA expression levels at diverse worm phases were assessed using qPCR as described previously [10]. The TsGSCP-specific primers used for qPCR were $5^{\prime}$-ATGCGGCTATGGATGTGA CGG-3' and 5'-GTGTGCACAACGGTGTTTCAGC$3^{\prime}$. The relative level of TsGSCP mRNA expression was normalized by subtracting the mRNA expression level of the T. spiralis internal control gene tubulin (GenBank: XM_003369432.1) [50] and then calculated according to the comparative Ct ${ }^{2-\Delta \Delta \mathrm{Ct})}$ method [20]. Each experiment was performed with three replicates.

\section{Indirect immunofluorescence (IIF) analysis}

IIF analysis was performed with whole worms and their cross sections as reported previously [51, 52]. Whole intact worms in different $T$. spiralis phases (ML, 6 and $12 \mathrm{~h} \mathrm{IIL}$, 3- and 6-day AWs, and NBL) were fixed with $4 \%$ paraformaldehyde at room temperature for $30 \mathrm{~min}$, washed three times with PBS, and then immobilized in cold acetone at $-20{ }^{\circ} \mathrm{C}$ for $20 \mathrm{~min}$. Moreover, the ML, IIL and AWs were embedded in paraffin, and 2- $\mu \mathrm{m}$-thick worm cross-sections were sliced with a microtome. Worm cross-sections were first blocked with goat serum and subsequently with $0.3 \% \mathrm{H}_{2} \mathrm{O}_{2}$ at room temperature for $20 \mathrm{~min}$. The parasites and cross-sections were probed with diverse sera (1:10; anti-rTsGSCP serum, infection serum, preimmune serum and anti-MBP-tag serum) at $37{ }^{\circ} \mathrm{C}$ for $2 \mathrm{~h}$. Following washes in PBS, the worms and cross-sections were incubated with FITC-conjugated anti-mouse IgG (1:100; Abways, Shanghai, China). After a rewash, the whole worms and cross-sections were examined under fluorescence microscopy (Olympus, Japan) $[53,54]$.

\section{Far-Western blotting showing rTsGSCP binding with IEC proteins}

IECs from the mouse intestine were sensitive to T. spiralis penetration, whereas mouse $\mathrm{C} 2 \mathrm{C} 12$ cells from a subpopulation of striated muscle myoblasts were insensitive to penetration and served as negative control cells [34, 55]. The binding of rTsGSCP and IECs was ascertained by far-Western blotting. Soluble IEC proteins were separated by SDS-PAGE, transferred onto NC membranes, cut into strips and blocked with 5\% skim milk. Following 
washes with PBST, the strips were incubated with $20 \mu \mathrm{g} /$ $\mathrm{mL}$ rTsGSCP at $37{ }^{\circ} \mathrm{C}$ for $2 \mathrm{~h}$, subsequently probed with anti-rTsGSCP serum and incubated with HRP-conjugated anti-mouse IgG (1:10 000, Southern Biotech). Finally, colour was developed with DAB (Sigma-Aldrich).

\section{Binding of rTsGSCP with IECs proteins as determined by ELISA}

Binding of rTsGSCP and IEC proteins was assessed by ELISA as reported previously [45]. Briefly, a plate was coated with diluted IEC proteins $(0.01,0.1,0.2,0.3$, $0.4,0.5$ and $0.6 \mu \mathrm{g} / \mathrm{mL}$ ) at $4{ }^{\circ} \mathrm{C}$ overnight. After being blocked with $5 \%$ skim milk and washed using PBST, the plates were incubated with diluted concentrations of rTsGSCP $(0.01,0.5,1,1.5,2,2.5$ and $3 \mu \mathrm{g} / \mathrm{mL})$ at $37^{\circ} \mathrm{C}$ for $2 \mathrm{~h}$. Following washing, the plates were probed with anti-rTsGSCP serum (1:100) and incubated with HRPconjugated anti-mouse IgG (1:10 000, Southern Biotech). Colour was developed using $o$-phenylenediamine dihydrochloride (OPD; Sigma-Aldrich), and absorbance at $492 \mathrm{~nm}$ was measured [56].

\section{IIF analysis of rTsGSCP and IEC binding}

The binding of rTsGSCP and IECs and its cellular localization were evaluated using IIF [56]. IECs were cultivated in a 6-well culture plate until confluent [57]. Then, the IECs were incubated with rTsGSCP $(20 \mu \mathrm{g} / \mathrm{mL})$ at $37{ }^{\circ} \mathrm{C}$ for $2 \mathrm{~h}$. Following washes, the IECs were fixed in cold acetone for $10 \mathrm{~min}$ and subsequently blocked with $5 \%$ goat serum at $37^{\circ} \mathrm{C}$ for $2 \mathrm{~h}$. IECs were incubated with anti-rTsGSCP immune sera (1:10 dilution) as the primary antibody. FITC-conjugated anti-mouse IgG (1:100; Abways) was used as the secondary antibody. Cell nuclei were stained with 4',6-diamidino-2-phenylindole (DAPI) and examined by fluorescence microscopy [22].

\section{Larval intrusion into IECs in vitro}

To investigate whether TsGSCP acts on larval intrusion into the intestinal epithelium, an in vitro intrusion assay was performed as previously described [9]. In brief, ML were first activated and transformed into IIL upon exposure to $5 \%$ mouse bile for $2 \mathrm{~h}$ at $37^{\circ} \mathrm{C}$. One hundred IIL were added to an IEC monolayer cultured in DMEM semisolid medium (DMEM supplemented with L-glutamine, $15 \mathrm{mM}$ HEPES, and $1.75 \%$ agarose). The medium was presupplemented with various concentrations of rTsGSCP $(1.5,3,6,9,12$ and $15 \mu \mathrm{g} / \mathrm{mL})$ or serially diluted anti-rTsGSCP serum (1:100-1:1000). After cultivation at $37{ }^{\circ} \mathrm{C}$ and $5 \% \mathrm{CO}_{2}$ for $2 \mathrm{~h}$, larval intrusion into the monolayer was observed by microscopy [48]. The invaded larvae were mobile and migrated into the monolayer, leaving a clear migratory trace, whereas noninvading larvae were coiled on the monolayer surface.

\section{RNAi analysis}

The TsGSCP-specific dsRNA target sequence of the complete TsGSCP cDNA sequence was used to design the primers (Table 1) [58]. To confirm TsGSCP-dsRNA specificity, a T. spiralis aspartyl aminopeptidase (TsAAP, GenBank: KRY29491.1) was selected as a specific control. Additionally, green fluorescent protein (GFP) dsRNA was also prepared as a control. dsRNA was transfected into $T$. spiralis larvae by electroporation and cultured in RPMI 1640 medium at $37{ }^{\circ} \mathrm{C}$ for $2-6$ days. qPCR and Western blotting were performed to assess TsGSCP expression in the ML as reported previously $[59,60]$, and the expression level of the $T$. spiralis housekeeping gene tubulin was used as the internal control. The protein expression level was assessed based on densitometry, and the results showed the relative protein expression as assessed in three repeated experiments [61].

The enzymatic activity of natural TsGSCP in crude soluble proteins of dsRNA-TsGSCP-transfected larvae was analysed and compared with that of untransfected larvae as previously described [22]. Briefly, ML and IIL were transfected with $40 \mathrm{ng} / \mu \mathrm{L}$ dsRNA-TsGSCP and cultured for 2 days, and somatic soluble proteins of dsRNAtreated ML and IIL were prepared. The enzymatic activity of native TsGSCP in worm crude proteins was ascertained using the cysteine protease-specific substrate Z-Phe-Arg-7-amido-4-methylcoumarin hydrochloride (Z-FR-AMC; Sangon, China).

\section{Challenge by infection with dsRNA-treated larvae in mice}

To evaluate larval infectivity, survival and fecundity in the host intestine following dsRNA interference, 30

Table 1 TsGSCP-specific primers flanked by T7 RNA polymerase promoter sequences

\begin{tabular}{|c|c|}
\hline Primers & Sequences \\
\hline T7-TsGSCP-F & 5'-GATCACTAATACGACTCACTATAGGGGCTAGAAAACGATGGCCACA-3' \\
\hline T7-TsGSCP-R & 5'-GATCACTAATACGACTCACTATAGGGGCCATTCCAGCTACAACATA-3' \\
\hline T7-GFP-F & 5'-GATCACTAATACGACTCACTATAGGGTCCTGGTCGAGCTGGACGG-3' \\
\hline T7-GFP-R & 5'-GATCACTAATACGACTCACTATAGGGCGCTTCTCGTTGGGGTCTTTG-3' \\
\hline
\end{tabular}

The underlined portion is the T7 promoter sequence 
mice were assigned to 3 groups (10 animals per group). Each mouse was inoculated orally with $500 \mathrm{ML}$ treated with $40 \mathrm{ng} / \mu \mathrm{L}$ dsRNA-TsGSCP, dsRNA-GFP or PBS. The infected mice were euthanized $5 \mathrm{dpi}$, adult worms were removed from the intestine, the adult worm burden was assessed, and adult worm morphology and size were examined by microscopy. Thirty adult females from each group of infected mice were cultured, and female reproductive ability (fecundity) was ascertained on the basis of NBL production by each female within $72 \mathrm{~h}$ [62].

\section{Statistical analysis}

All the data were analysis with SPSS 21.0 software. The results are shown as the means \pm standard deviation (SD). TsGSCP expression level, worm burden and length, and NBL production among different groups were analysed with one-way ANOVA. Chi-square test was performed to analyse the larval invasion rate and TsGSCP expression after RNAi in the various groups. $P<0.05$ is considered to be statistically significant.

\section{Results}

\section{Bioinformatics analysis of TsGSCP}

The CDS of TsGSCP is 991 bp, encoding 325 amino acids with a relative molecular weight of $36.9 \mathrm{kDa}$ and isoelectric point (pI) of 6.88. TsGSCP does not contain a transmembrane region, but it has a signal peptide. The subcellular location is a secretory pathway, indicating that the TsGSCP protein may be a secretory protein. The tertiary structure of TsGSCP has 4 active enzymatic sites (His, Gln, Cys and Asn). Using BioEdit software to compare the TsGSCP amino acid sequences in different Trichinella species, the following results were obtained: the amino acid sequence of TsGSCP shared 98\% identity with cysteine protease of T. nelsoni, Trichinella T8 and T. nativa, $97 \%$ identity with those of T. patagoniensis and Trichinella T6, 90\% identity with those of T. papuae and T. zimbabwensis, and 89\% with T. pseudospiralis (Figure 1). The results indicated that TsGSCP is highly similar between encapsulated Trichinella species, suggesting that TsGSCP is not species-specific. A Phylogenetic tree analysis of TsGSCP and cysteine proteases in other organisms is shown in Figure 2. The phylogenetic tree showed that a monophyletic group of the genus Trichinella was well supported. Within the genus Trichinella, two clades were obvious: one was the encapsulated species clade (T. spiralis, T. nelsoni, T. patagoniensis, T6, T. nativa, and T8), and the other was the nonencapsulated species clade ( $T$. pseudospiralis, T. papuae and T. zimbabwensis).

\section{Analyses of rTsGSCP expression and antigenicity}

In the SDS-PAGE analysis, purified rTsGSCP was identified as a clearly visible individual band, and its molecular weight $(74.2 \mathrm{kDa})$ was consistent with its predicted size (rTsGSCP is $34.2 \mathrm{kDa}$, and the MBP-tag protein is $40 \mathrm{kDa}$ ) (Figure 3). The serum anti-rTsGSCP IgG titre

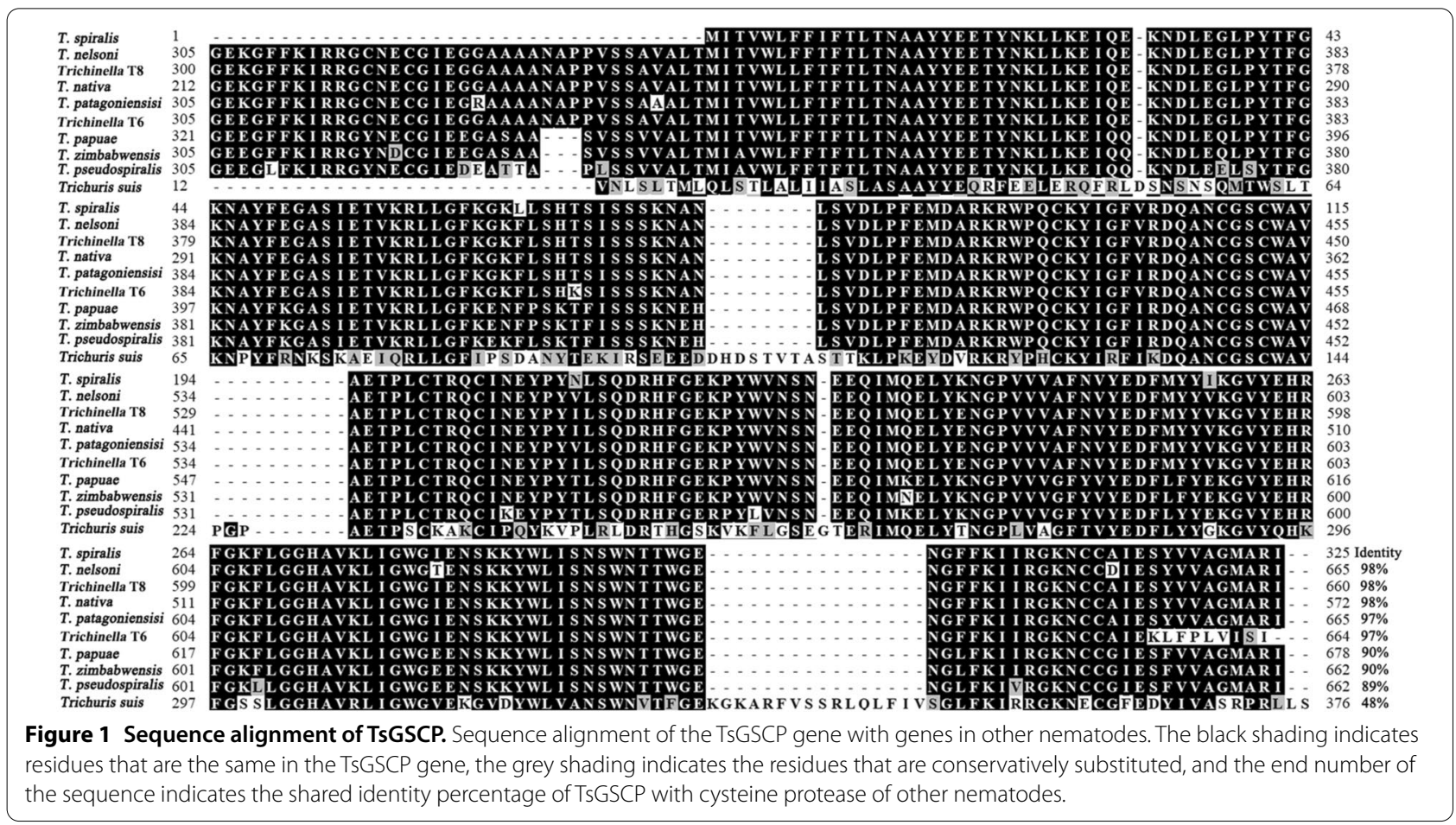




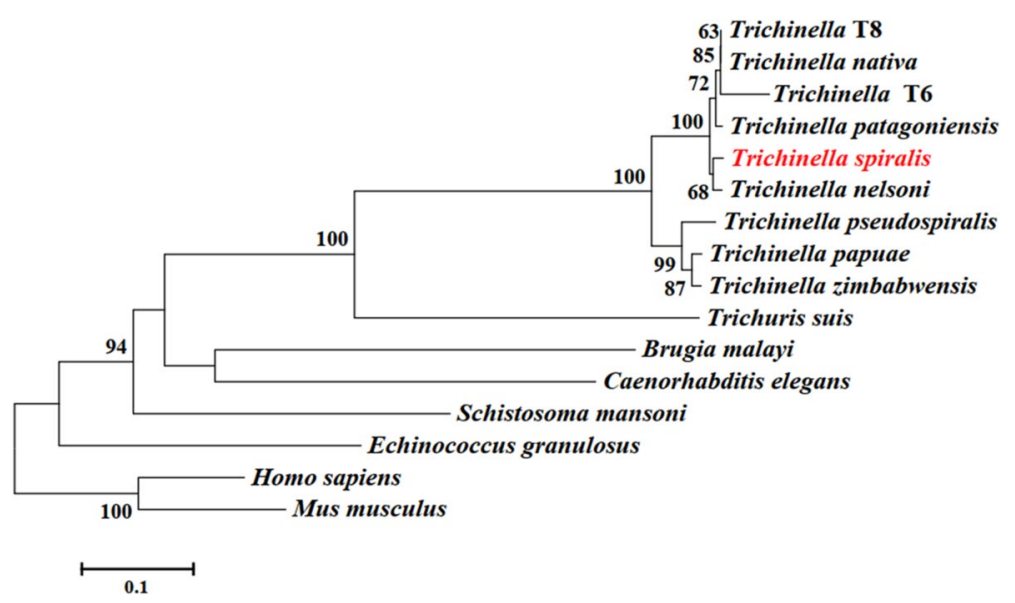

Figure 2 Phylogenetic tree of cysteine proteases in 16 organisms as produced through the NJ method (the red font represents TsGSCP).
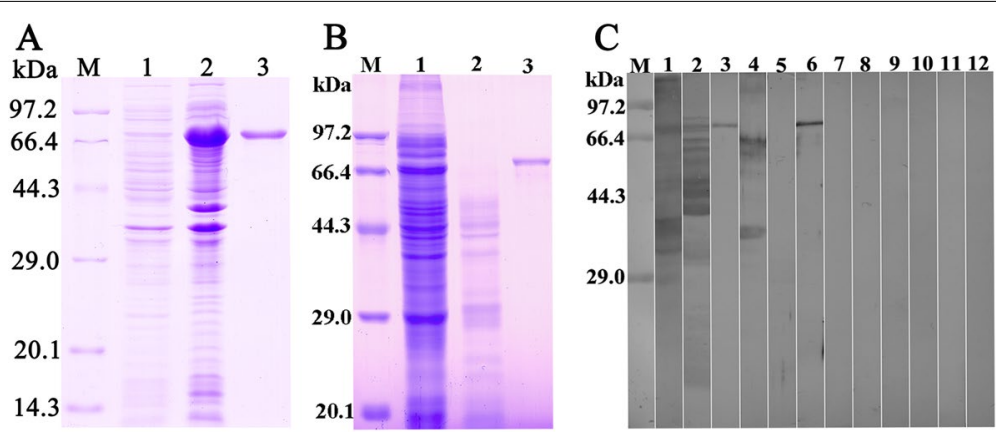

Figure 3 Expression and antigenicity analyses of rTsGSCP. A SDS-PAGE gel showing rTsGSCP. Lane M, protein marker; lane 1, lysate of bacteria carrying pMAL-c2x/TsGSCP prior to induction; lane 2, lysate of induced bacteria carrying pMAL-c2x/TsGSCP; lane 3, purified pMAL-c2x/TsGSCP. B SDS-PAGE gel showing of worm antigens. Lane M, protein marker; lane 1, IIL soluble crude proteins; lane 2, IIL ES proteins; lane 3, purified rTsGSCP. CWestern blot analysis of rTsGSCP. IIL soluble protein (lane 1), IIL ES protein (lane 2) and rTsGSCP (lane 3) were recognized with infection serum. Natural TsGSCP in IIL crude proteins (lane 4) and rTsGSCP (lane 6) were identified with anti-rTsGSCP serum, but native TsGSCP was not found among IIL ES proteins (lane 5) when probed with anti-rTsGSCP serum. Crude IIL (lanes 7 and 10), ES proteins (lanes 8 and 11), and rTsGSCP (lanes 9 and 12) were not recognized by preimmune serum (lanes 7-9) or anti-MBP-tag serum (lanes 10-12).

was $1: 10^{5}$ following the final immunization, demonstrating that rTsGSCP induced immunogenicity. The results of the Western blot analysis showed that rTsGSCP was recognized by anti-rTsGSCP serum and infection serum but not by anti-MBP-tag serum and preimmune serum. Furthermore, natural TsGSCP of 35.2, 49.6, 56.5, $61.6 \mathrm{kDa}$ in IIL soluble proteins was identified by antirTsGSCP serum but was not found among IIL ES proteins, suggesting that TsGSCP is a somatic worm protein, not a secretory protein.

\section{TsGSCP mRNA and protein expression in different stages} The qPCR results showed that TsGSCP transcription level in the IIL stage was significantly higher than that in the worms at other stages $(F=4.840, P<0.05)$ (Figure 4A). Moreover, the TsGSCP expression level in the
IIL stage was higher than that in the ML or AW stage $(F=7.778, P<0.05)$ (Figure 4B). These results indicated that both TsGSCP mRNA and protein expression in the IIL stage was higher than that in the other developmental stages of the T. spiralis lifecycle, suggesting that TsGSCP might be a larva intrusion-related protein.

\section{Expression and tissue localization of natural TsGSCP in $T$. spiralis}

An IIF analysis was performed to assess the expression and localization of TsGSCP in T. spiralis. The results are shown in Figure 5. In anti-rTsGSCP serum, bright green fluorescence was observed on the cuticle surface of worms in each stage except those in the muscle larva stage. In the IIF analysis performed with worm 

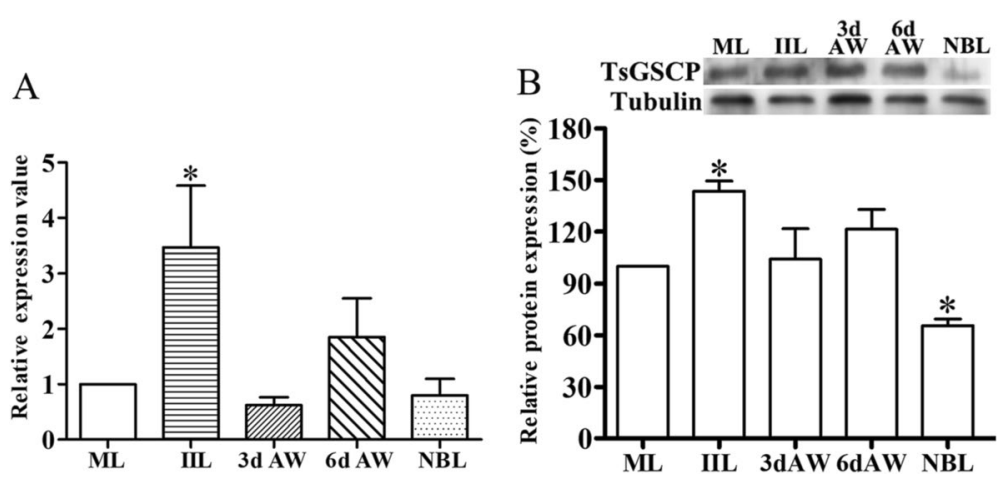

Figure 4 TsGSCP transcription and expression in the lifecycle of $\boldsymbol{T}$. spiralis. A qPCR assay of TsGSCP transcription in different worm phases. B Western blot results showing TsGSCP expression in different stages based on three independent densitometry tests. The relative transcription and expression level of TsGSCP at the IIL stage was clearly higher than at other worm stages $\left({ }^{*} P<0.05\right)$.

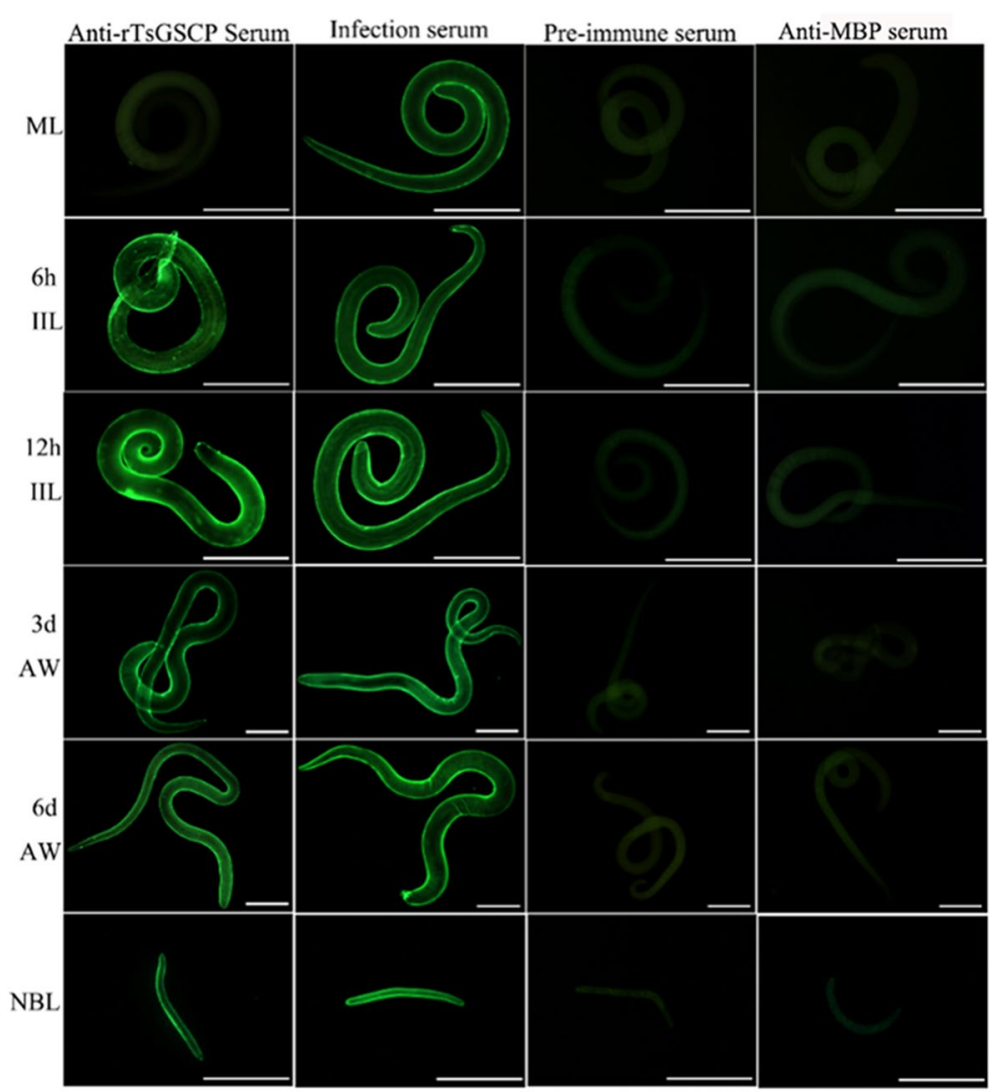

Figure 5 Expression of TsGSCP on the cuticle of $T$. spiralis in different stages, as identified by IIF analysis with anti-rTsGSCP serum. Bright fluorescence staining was observed on the outer surface of cuticles in worms at each stage except the muscle larva stage. The nematodes recognized with infection serum were used as positive controls; preimmune serum and anti-MBP-tag serum were used as the negative controls. Scale bar of ML and IIL $=50 \mu \mathrm{m}$, Scale bar of AWs $=100 \mu \mathrm{m}$, Scale bar of $\mathrm{NBL}=25 \mu \mathrm{m}$.

cross-sections, the fluorescence staining was principally located in the cuticle of ML and IIL and female intrauterine embryos in the nematode (Figure 6).
Binding of rTsGSCP and IEC proteins as assessed with far-Western blotting and ELISA

The SDS-PAGE results revealed that soluble IEC proteins separated into approximately 28 bands in a range between 


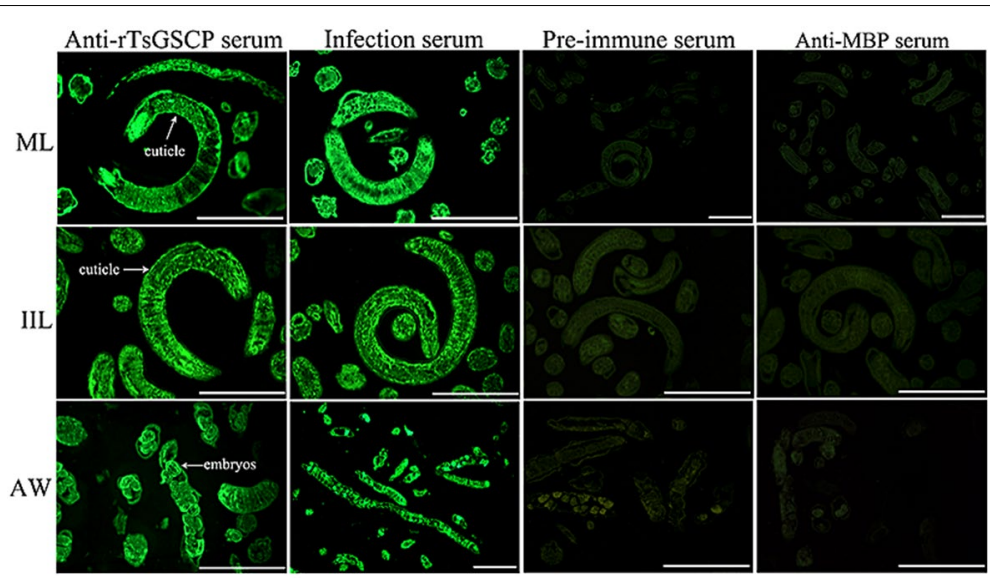

Figure 6 Tissue localization of TsGSCP in T. spiralis in different stages. IIF analysis with worm cross-sections was performed using anti-rTsGSCP serum. Immune staining was primarily localized in the cuticle of ML and IIL and female intrauterine embryos in the nematode. No immune staining in worm cross-sections was observed with preimmune serum or anti-MBP serum, which were the negative controls. Scale bars, $50 \mu \mathrm{m}$.

20.1 and $97.2 \mathrm{kDa}$ (Figure 7A). In far-Western blotting, after IEC proteins were incubated with rTsGSCP, 7 bands (96.2, 70.8, 63.6, 56.4, 47.4, 38.8 and $36.4 \mathrm{kDa}$ ) were identified with anti-rTsGSCP serum, and 6 bands (97.2, 75.0, $62.7,57.9,46.4$ and $41.9 \mathrm{kDa}$ ) were detected with infection serum. No IEC proteins preincubated with rTsGSCP were identified with preimmune serum, and no $\mathrm{C} 2 \mathrm{C} 12$ proteins preincubated with rTsGSCP were detected by anti-rTsGSCP serum or infection serum (Figure 7B). These results indicated that TsGSCP specifically binds to IEC proteins.
The ELISA results showed an evident interaction of rTsGSCP with IEC proteins. The absorbance measure of the IEC proteins was dose-dependent $(r=0.994$, $P<0.0001)$ and showed an increasing trend with increasing IEC protein coating concentration $(F=397.007$, $P<0.0001$ ) (Figure 8A). Moreover, the absorbance was rTsGSCP dose-dependent $(r=0.976, \quad P<0.0001)$ and showed a positive trend with increasing rTsGSCP dose $(F=99.967, P<0.0001)$ (Figure $8 B)$. The results demonstrated that rTsGSCP can bind to IEC proteins, which might play a major role in larval intrusion into IECs.

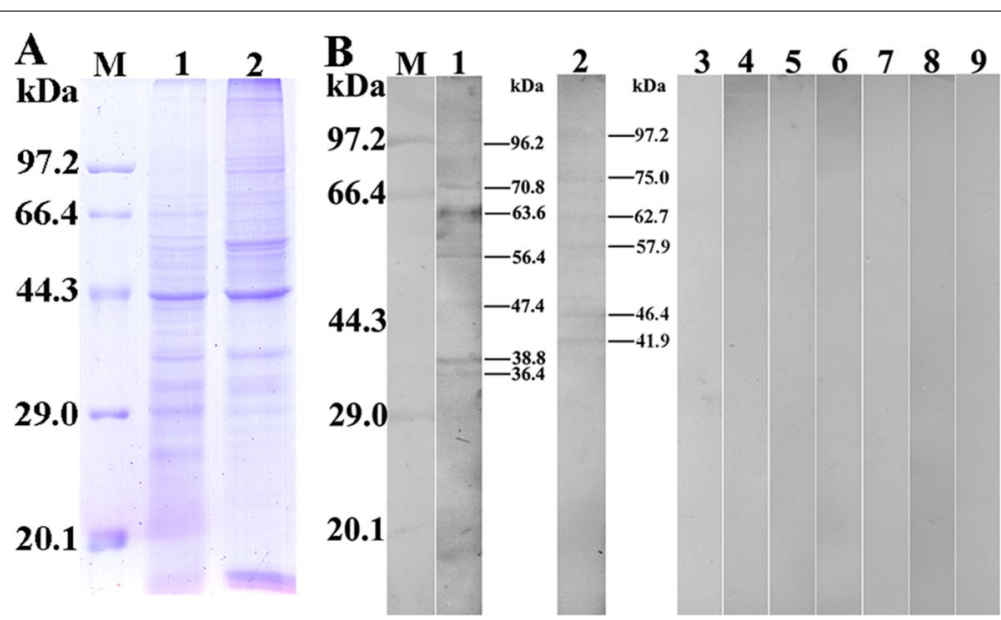

Figure 7 Far-Western blot identification of binding between rTsGSCP and IEC proteins. A SDS-PAGE analysis of soluble IEC proteins (lane 1) and $\mathrm{C}_{2} \mathrm{C} 12$ cell proteins (lane 2). Lane M, protein marker. B Far-Western blotting showing the binding of rTsGSCP with IEC proteins. Lane M, protein marker. The strips containing IEC protein (lanes 1-6) were incubated with rTsGSCP (lanes 1-3) or MBP (lanes 4-6). Bands of indicative of rTsGSCP binding with IECs were identified with anti-rTsGSCP serum (lane 1) and infection serum (lane 2) but not with preimmune serum (lane 3). No binding of MBP with IECs was detected with anti-MBP serum (lane 4), infection serum (lane 5) or preimmune serum (lane 6). There was no binding of rTsGSCP with C2C12 cells when anti-rTsGSCP serum (lane 7), infection serum (lane 8) or preimmune serum (lane 9) was used. 

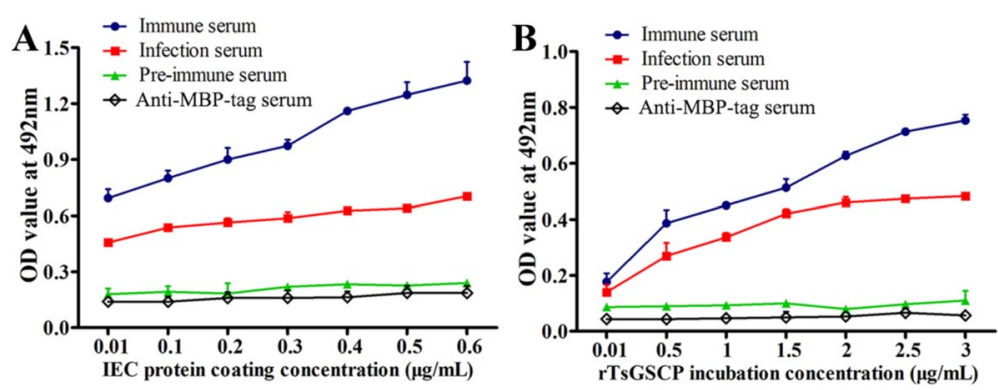

Figure 8 Binding of rTsGSCP with IECs as detected by ELISA. A Binding of IEC proteins with diluted coating and incubation with $1 \mu \mathrm{g} / \mathrm{mL}$ rTsGSCP. B Binding of $1 \mu \mathrm{g} / \mathrm{mL}$ IEC protein with coating and incubation with different doses of rTsGSCP. The binding between rTsGSCP and IEC proteins is dose-dependent.

\section{Binding of rTsGSCP with IECs and its cellular localization}

The IIF analysis results showed that after IECs were preincubated with rTsGSCP, green immunofluorescence staining was observed on the surface of the IECs probed with anti-rTsGSCP serum and infection serum but not with preimmune serum. The IECs preincubated with MBP alone did not show any immune staining upon treatment with anti-rTsGSCP serum or infection serum. No immune staining on the $\mathrm{C} 2 \mathrm{C} 12$ surface was detected when $\mathrm{C} 2 \mathrm{C} 12$ cells preincubated with rTsGSCP were probed with anti-rTsGSCP serum or infection serum (Figure 9A). At high magnification, immune staining was observed to be distributed in the cytoplasm of IECs (Figure 9B), suggesting that rTsGSCP has specific binding ability with IECs and enters the cytoplasm.

\section{rTsGSCP promotion and anti-rTsGSCP serum suppression of larval intrusion}

As shown in Figure 10A, invaded larvae left a clear migratory trace (red arrow), and uninvaded larvae were coiled on the monolayer surface (Figures $10 \mathrm{~B}$ and C). After the medium was supplemented with rTsGSCP and IIL were cultured in this medium for $2 \mathrm{~h}$, rTsGSCP significantly accelerated larval intrusion. This acceleration was rTsGSCP dose-dependent $(r=0.950, P<0.0001)$ and exhibited an increasing trend with increasing rTsGSCP dose $(F=228.325, \quad P<0.0001)$, but MBP-tag did not facilitate intrusion (Figure 10D). When the medium was supplemented with different dilutions of anti-rTsGSCP serum, anti-rTsGSCP serum (1:100-1:400) significantly impeded larval intrusion relative to PBS $\left(\chi^{2}=16.743\right.$, $P<0.0001)$. The suppression of IEC intrusion was dosedependent for anti-rTsGSCP antibodies $(r=0.969$, $P<0.0001)$, and the suppressive effect was reduced with increasing serum dilution $(F=136.542, P<0.0001)$ (Figure $10 \mathrm{E})$. Furthermore, the invasion rate of IECs with IIL treated with dsRNA-TsGSCP, dsRNA-GFP and PBS was $53.39,68.9$ and $71.2 \%$, respectively $(P<0.05)$, and the invasive ability of the larvae treated with dsRNA-TsGSCP was inhibited by $25.02 \%$ compared to that of the dsRNAGFP group $\left(\chi^{2}=5.578, P<0.05\right)$ (Figure 10F). These results suggested that TsGSCP promoted larval intrusion, whereas anti-rTsGSCP antibodies and silencing of the TsGSCP gene inhibited larval intrusion, indicating that TsGSCP plays an important role in larval intrusion into host gut epithelium during Trichinella spiralis infection.

\section{Reduction in TsGSCP expression and activity after TsGSCP gene silencing}

After transfection with $40 \mathrm{ng} / \mu \mathrm{L}$ dsRNA and cultured for 2 days, the survival of the dsRNA-TsGSCP, dsRNAGFP and PBS larva groups was 99.60, 99.44 and 99.63\%, respectively $\left(\chi^{2}=2.007, P>0.05\right)$, indicating that electroporation has no evident effect on worm survival. When the ML were treated with 20,40 and $60 \mathrm{ng} / \mu \mathrm{L}$ dsRNA and cultivated for 2 days, TsGSCP transcription levels were decreased by $14.82,33.30$ and $62.13 \%$, respectively, compared to those in the PBS group $(P<0.05)$, and TsGSCP expression was reduced by $22.24,45.28$ and $60.51 \%(P<0.05)$ (Figures $11 \mathrm{~A}$ and $\mathrm{B})$. Two, four and 6 days after treatment with $40 \mathrm{ng} / \mu \mathrm{L}$ dsRNA-TsGSCP, TsGSCP transcription levels were reduced by $24.25,2.21$ and $1.89 \%$, respectively $(P<0.05)$, and TsGSCP expression was suppressed by 46.82, 1.73 and $2.26 \%$, respectively $(P<0.05)$ (Figures $11 C$ and D). However, TsGSCP expression levels were not suppressed when the worms were transfected with control dsRNA-GFP. Moreover, no obvious change in TsAAP expression was observed in ML treated with dsRNA-TsGSCP (Figure 11E), demonstrating that the dsRNA is TsGSCP-specific.

The results of the enzymatic activity assay showed that the natural TsGSCP activity among the crude proteins of dsRNA-treated ML and IIL was reduced by 37.39 and $28.00 \%$, respectively, compared with untreated ML or IIL $\left(\chi_{M L}^{2}=45.399\right.$ and $\left.\chi^{2}{ }_{I L}=23.464, P<0.05\right)$ (Figure $\left.11 \mathrm{~F}\right)$. 


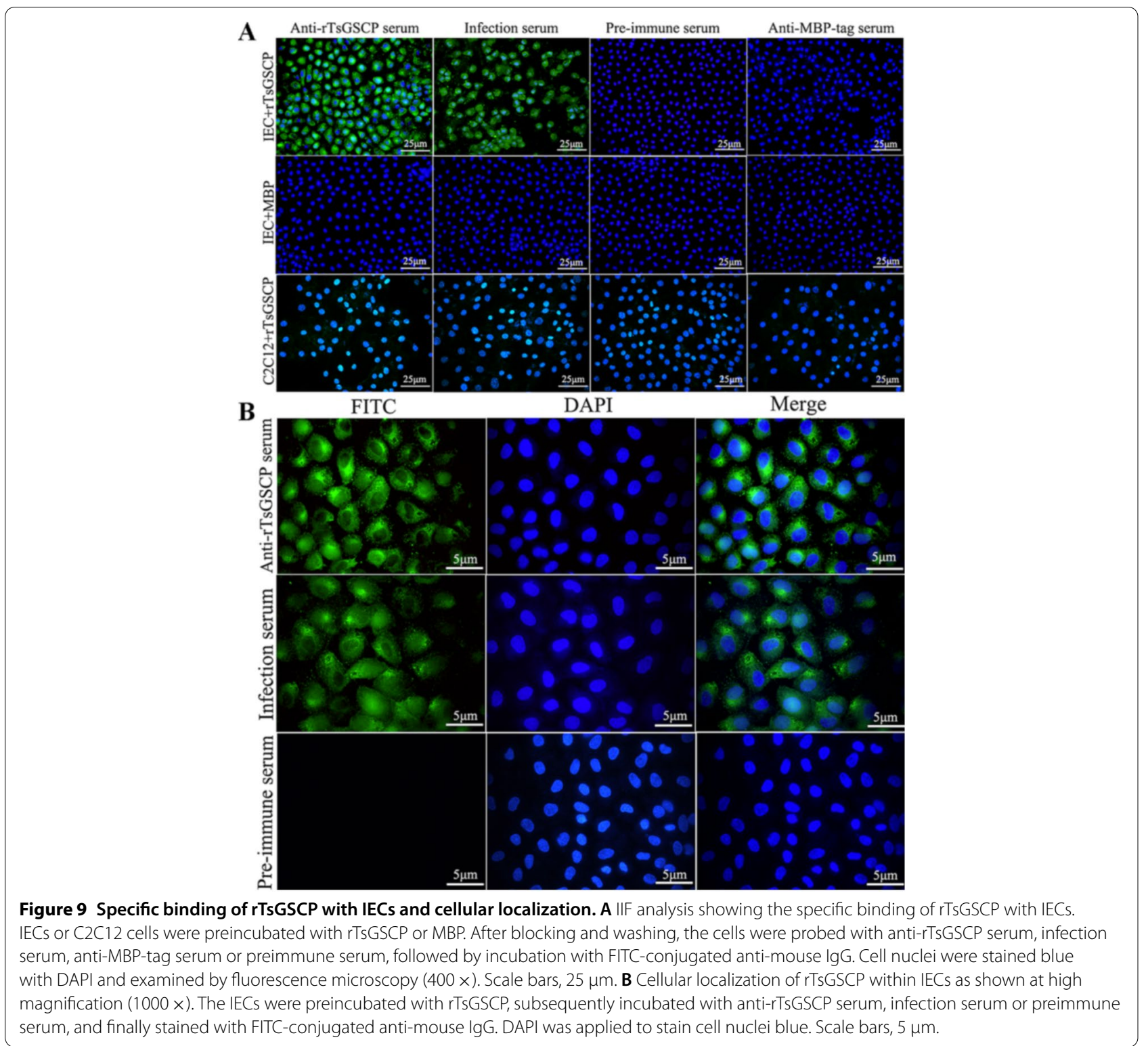

\section{dsRNA-TsGSCP impaired larval infectivity, growth and fecundity}

The number of 5 dpi adult worms in mice challenged with dsRNA-TsGSCP-transfected ML was $35.15 \%$ less than that in the PBS group $(F=37.374 P<0.001)$, and the control dsRNA-GFP group did not show any decrease in adult worm burden $(P>0.05)$ (Figure 12A). The adult female length in the dsRNA-TsGSCP group was significantly shorter than that in the control dsRNA and PBS groups $\left(F=21.082, P^{<} 0.001\right)$ (Figure $12 \mathrm{~B}$ ), but male length showed no apparent change. Female fecundity in the dsRNA-TsGSCP transfection group worms was also evidently lower than that of the PBS group worms $(F=18.728, P<0.001)$, but there were no significant differences in female fecundity between the control dsRNA-GFP and PBS groups $(P>0.05)$ (Figure 12C), demonstrating that silencing of the TsGSCP gene significantly impaired larval infectivity, development and survival and profoundly reduced female fertility.

\section{Discussion}

Cysteine proteases usually consist of the enzyme precursor sequence and mature enzyme domain. They are usually nonenzymatic in the form of proenzymes but can self-hydrolyse as precursor peptides under acidic conditions and become catalytic enzymes [63]. Cysteine proteases have been extensively studied, and cathepsin B 

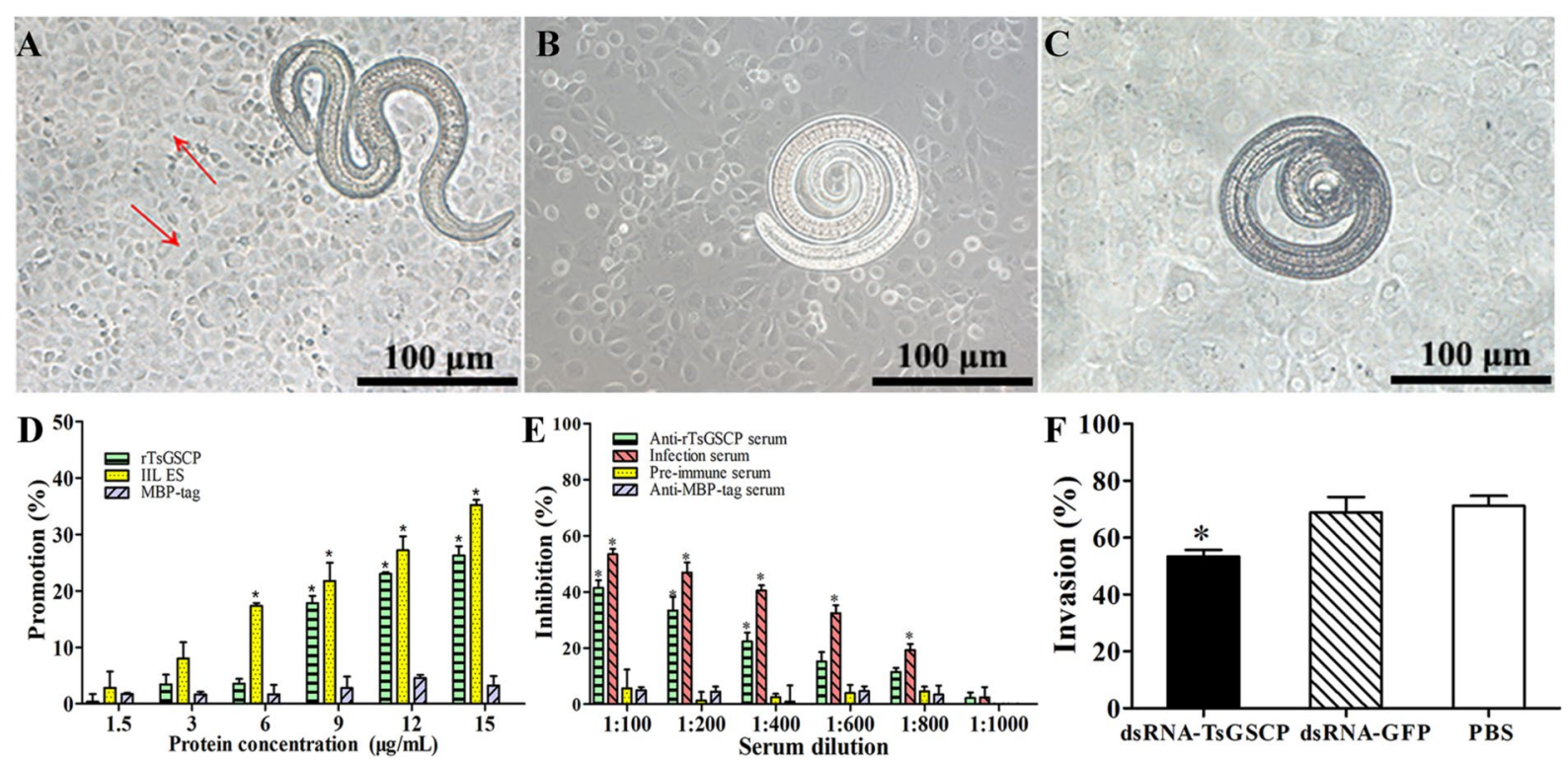

Figure 10 Facilitation or inhibition of larval intrusion by rTsGSCP or anti-rTsGSCP serum. IILI were added to an IEC monolayer, and invaded larvae were examined under a microscope $2 \mathrm{~h}$ after cultivation. A The invading larvae were mobile and migratory in the monolayer (the red arrow shows migratory trace); noninvading worms were coiled on the surface of the IECs (B) and C2C12 cells (C). D rTsGSCP accelerated worm intrusion. $\mathbf{E}$ Anti-rTsGSCP serum suppressed larval intrusion. F: dsRNA-TsGSCP inhibited larva invasion into IECs. ${ }^{*}<<0.0001$ compared to the PBS control groups. Scale bars, $100 \mu \mathrm{m}$.

has been found to function either as an endopeptidase cleaving internal peptide bonds or as an exopeptidase (with carboxydipeptidase activity) acting on the end of the peptide chain [64]. Many studies on parasites have shown that cysteine protease may be the key to immune escape, encystation/excystation, moulting, and tissue cell invasion of parasites [31]. The mRNA encoding cathepsin B-like cysteine proteases (CATBs) is highly expressed in the genome of haemophagous nematodes, and the CATBs of hookworm (Necator americanus) are mainly localized in intestinal tissue [65]. Previous studies have shown that cathepsin B- and L-like proteases facilitate helminth larva invasion into host tissues [29]. A cathepsin B-like protease (Ac-cathB-1) is involved in host enteral epithelium invasion by Angiostrongylus cantonensis; incubation of rat intestine with Ac-cathB-2 resulted in the detachment of epithelial cells, and antiserum reduced L3 larva penetration [66]. Our previous study indicated that recombinant $T$. spiralis cathepsin B ( $\mathrm{rTs} C \mathrm{~B}$ ) facilitated larva penetration into IECs, whereas anti-rTsCB antibodies and RNAi suppressed larva penetration into enterocytes, suggesting that $\mathrm{Ts} C \mathrm{~B}$ participated in larva invasion into the gut epithelium and might be a molecular target against T. spiralis intrusion [24].

In the present study, bioinformatics analyses showed that TsGSCP has a functional cathepsin B domain; cathepsin $\mathrm{B}$ belongs to the C1A peptidase family. TsGSCP was cloned into the pMAL-c2x expression vector and expressed in an E. coli expression system. Following purification, rTsGSCP was used to immunize mice and produce anti-rTsGSCP antibodies. The anti-rTsGSCP IgG titre was $10^{5}$ two weeks after the final immunization, which indicated that rTsGSCP has strong immunogenicity. In the Western blotting analysis, rTsGSCP was recognized by anti-rTsGSCP serum and infection serum. As shown in Figure 3C, several native TsGSCPs of 35.2$61.6 \mathrm{kDa}$ among IIL soluble proteins were identified with anti-rTsGSCP serum but was not found among IIL ES proteins, suggesting that TsGSCP is a somatic worm protein, not secretory protein. The presence of several native TsGSCPs among IIL somatic proteins might be a result of different TsGSCP isoforms or post-translational modification and processing. It is likely that, as a member of the T. spiralis cathepsin B family, TsGSCP has the same antigenic epitopes as cathepsin B [26, 42, 49, 67].

The qPCR and Western blot analysis results showed that TsGSCP mRNA and protein expression at the IIL stage was higher than that at other developmental stages in the T. spiralis lifecycle. The results of the IIF analysis with intact worms showed native TsGSCP on the outer cuticle of intestinal IIL, AW and NBL but not on that of ML. As identified by immunohistological staining, native TsGSCP was principally located at the cuticle and intrauterine embryos of the nematode. The expression of TsGSCP in all lifecycles of the nematode suggested that this protease participates in $T$. spiralis 


\section{A}

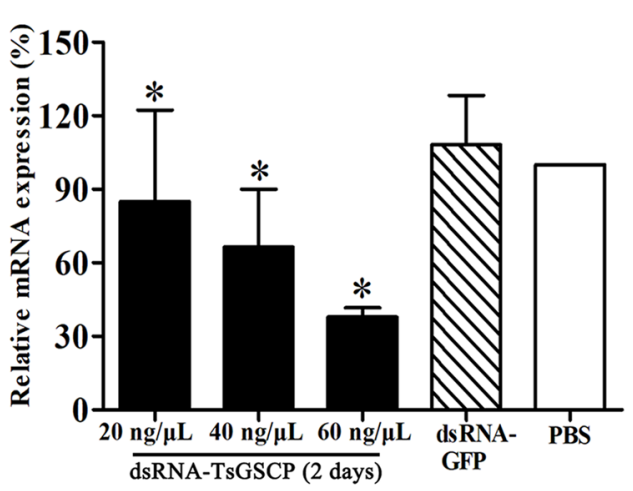

C

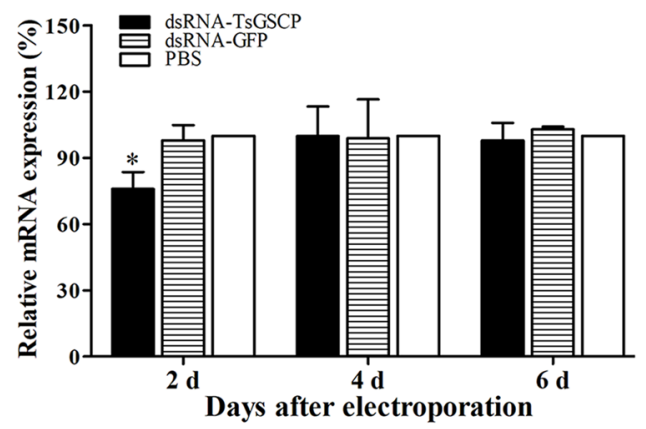

$\mathbf{E}$

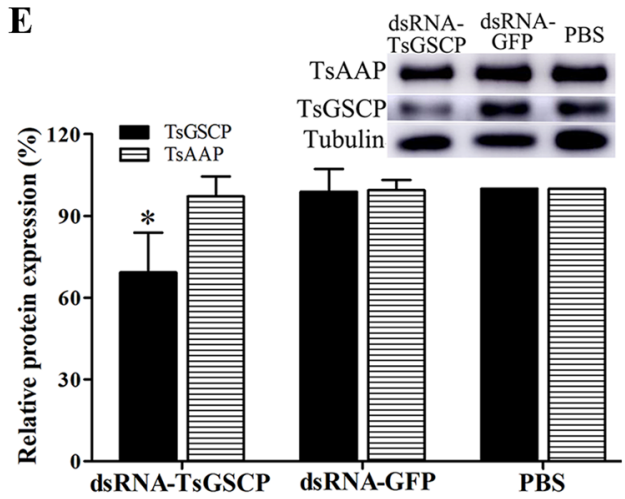

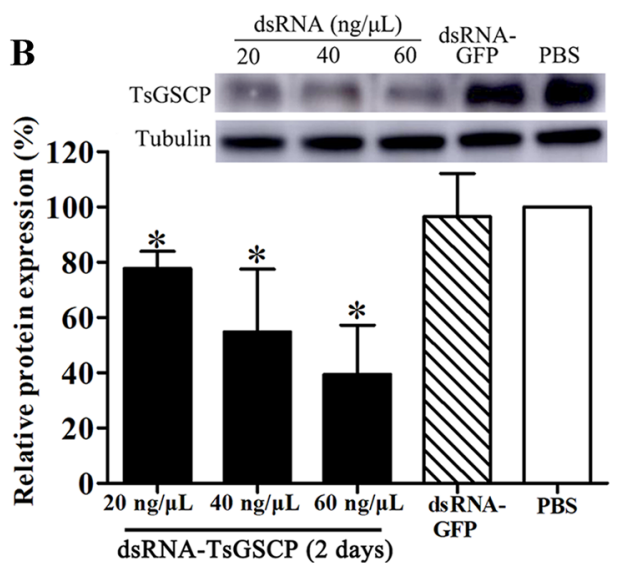

D
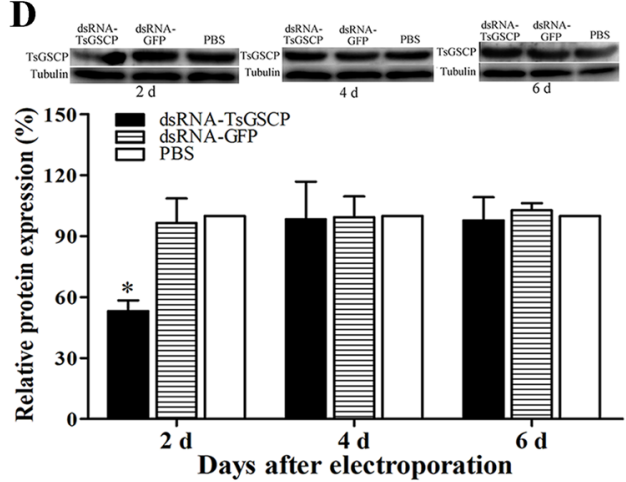

F

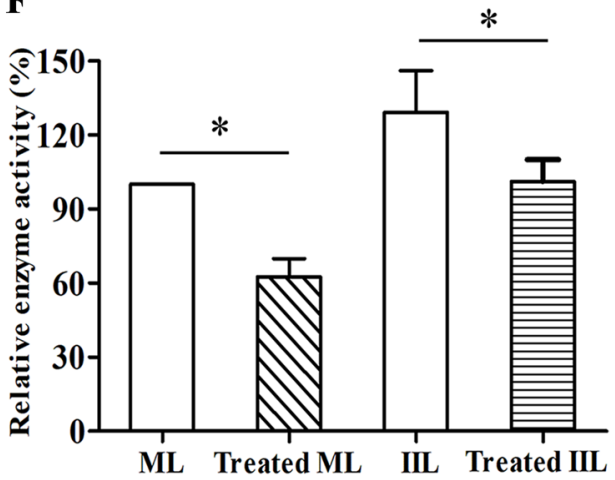

Figure 11 Suppression of TsGSCP expression and enzymatic activity after dsRNA interference. A Various doses of dsRNA-TsGSCP inhibited TsGSCP transcription. B Various doses of dsRNA-TsGSCP inhibited TsGSCP expression. C TsGSCP transcription level on different days after dsRNA transfection. D TsGSCP expression level as measured on different days after dsRNA transfection. E Expression levels of TsGSCP and T. spiralis aspartyl aminopeptidase (TsAAP) in ML treated using TsGSCP-specific dsRNA. F The ability of TsGSCP to enzymatically cleave substrate Z-FR-AMC was significantly reduced in dsRNA-TsGSCP-treated $\mathrm{ML}$ and IIL. ${ }^{*} P<0.05$ relative to the PBS group.

growth, development and survival in the host [16, 41]. Moreover, native TsGSCP on the outer cuticle of intestinal IIL the first exposure of the parasite to the enteral milieu of the host, where it is contacted and recognized by IECs; hence, TsGSCP might be a key intrusion-related protease in the IIL stage $[10,26,36]$. In this work, the enzymatic activity of rTsGSCP, which hydrolysed the cathepsin substrate, was not observed (data not shown). In the present study, the enzymatic activity of rTsGSCP was assessed by using gelatine zymography and cysteine protease-specific substrate (Z-FR-AMC). Unfortunately, rTsGSCP did not degrade gelatine or the substrate (data not shown), indicating that rTsGSCP does not have the enzymatic activity of native cysteine protease. The 

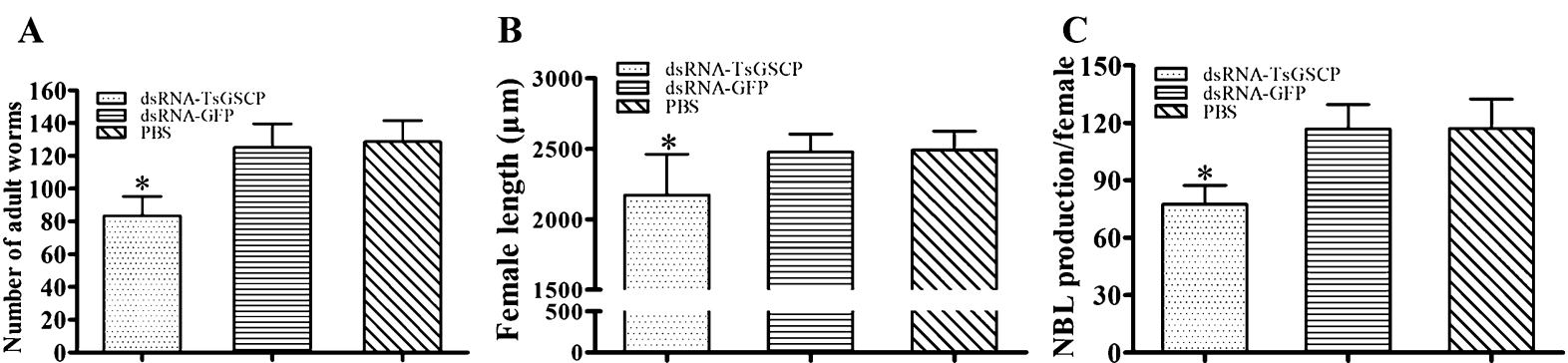

Figure 12 Intestinal adult worm burden and female length and fecundity in mice infected with larvae treated with TsGSCP dsRNA. A Intestinal adult worm burden $(n=10)$. B Adult female length $(n=25)$. C Female fecundity $(n=30)$. The data are shown as the means \pm SD of the dsRNA-TsGSCP, control dsRNA-GFP and PBS groups. ${ }^{*} P<0.001$ relative to the dsRNA-GFP control and PBS groups,

absence of native cysteine protease activity by rTsGSCP is likely a result of improper folding form of rTsGSCP in E. coli [22]. Therefore, to obtain rTsGSCP with enzymatic activity, a eukaryotic expression system needs to be used or native TsGSCP needs to be isolated from T. spiralis larvae.

Protein-protein interactions between rTsGSCP and IECs were also investigated in this study. The far-Western blot and ELISA results showed that rTsGSCP specifically bound to IEC proteins in a dose-dependent manner. The IIF analysis results indicated that the binding sites of rTsGSCP and IECs were located in the cytoplasm. Previous studies have shown that when IIL were incubated with IECs, some proteases produced by IIL entered the IECs $[18,47]$. The in vitro larval intrusion test showed that rTsGSCP markedly accelerated the worm intrusion into IECs, whereas anti-rTsGSCP antibodies profoundly impeded intrusion, and this acceleration and prevention was dependent on the dose of rTsGSCP and anti-rTsGSCP antibodies, respectively. The accelerated intrusion might be due to the specific binding of TsGSCP with IECs [22, 24]. The suppressive function of antirTsGSCP antibodies on larval intrusion into IECs might be a result of the cap-like antigen-antibody complex formed by TsGSCP and anti-TsGSCP antibodies at the larval anterior, which physically encloses the larval sensory receptors and interdicts the direct contact between IIL and the gut epithelium, impeding larval intrusion and penetration $[16,68]$. However, it is necessary to characterize the IEC proteins that bind with TsGSCP using coimmunoprecipitation/mass spectrometry in further investigations.

In the parasitic nematode T. spiralis, RNAi is the primary technique used to investigate gene function [59]. To verify the biological roles of TsGSCP in the intrusion in this study, growth and survival of this nematode, TsGSCP-specific dsRNA was transfected into ML via electroporation. The results showed that after the ML were treated with $40 \mathrm{ng} / \mu \mathrm{L}$ dsRNA and cultured for 2 days, TsGSCP mRNA and protein expression was reduced by 24.25 and $46.82 \%$, respectively. Natural TsGSCP activity in dsRNA-treated ML and IIL was inhibited by 37.39 and $28.00 \%$, respectively. The number of dsRNA-treated larvae intruding into IECs in vitro was decreased by $25.02 \%$ compared to that of the control group. These results indicated that silencing of the TsGSCP gene by a specific dsRNA significantly decreased TsGSCP expression and enzymatic activity in larvae and dramatically suppressed the ability of larvae to intrude into IECs. The results further verified that TsGSCP facilitates gut epithelium intrusion by $T$. spiralis [21]. Moreover, an animal challenge experiment revealed a $35.15 \%$ reduction in enteral adult worm burden in mice 5 dpi with dsRNA-transfected ML. Enteral worm growth and female fertility were also obviously impaired by TsGSCPspecific dsRNA, as demonstrated by shorter adults and lower female reproductive capacity. In a previous study, silencing cysteine protease genes (FhCatB1 and FhCatL1) in newly excysted juvenile Fasciola hepatica by RNAi reduced gut penetration [69]. In another study, Schistosoma japonicum cathepsin B2 promoted skin invasion, while anti-rsjCB2 IgG clearly inhibited cercariae invasion into the skin [70]. These findings indicated that TsGSCP exerts a principal role in gut mucosal invasion, larval growth and female fecundity during $T$. spiralis infection [22].

In conclusion, TsGSCP was highly expressed at gut invasive IIL stages of the $T$. spiralis lifecycle and primarily localized to the cuticle and intrauterine embryos of this parasite. The rTsGSCP showed good immunogenicity. rTsGSCP exhibited the ability to specifically bind with IECs, and the binding site is within the cytoplasm of the IECs. rTsGSCP accelerated larval intrusion into IECs, whereas anti-rTsGSCP antibodies impeded larval intrusion; the acceleration/inhibition effect was dose-dependent for rTsGSCP/anti-rTsGSCP antibodies. 
Silencing of the TsGSCP gene by specific dsRNA significantly decreased TsGSCP expression and TsGSCP ability to hydrolyse the cysteine protease substrate Z-FR-AMC; RNAi also impaired larval invasive ability, growth and fecundity. These findings demonstrated that TsGSCP plays a principal role in gut intrusion, worm development and fecundity during the $T$. spiralis lifecycle and might be a candidate target for vaccine development against Trichinella intrusion and infection.

\begin{abstract}
Abbreviations
AWs: adult worms; DAB: 3,3'-Diaminobenzidine tetrahydrochloride; DAPI: 4',6-Diamidino-2-phenylindole; ES: excretory/secretory; HRP: horseradish peroxidase; IIF: indirect immunofluorescence; IIL: intestinal infective larvae; IPTG: Isopropyl $\beta$-D-1-thiogalactopyranoside; ML: muscle larvae; NBL: newborn larvae; NC: nitrocellulose; OD: optical density; PBS: phosphate-buffered saline; rTsGSCP: recombinant T. spiralis gut-specific cysteine protease; TBST: Tris-buffered saline containing Tween.
\end{abstract}

\section{Acknowledgements}

We thank Ms. YY Song and Ms. Zhen Wang for helping with the animal experiments conducted in this study.

\section{Authors' contributions}

Conceptualization: JC, ZQW. Data analysis: YYH. Funding acquisition: JC, ZQW. Investigation: YYH, RZ, SWY, WWY, JHZ, RDL, SRL, JC, ZQW. Methodology: JC, ZQW. Project administration: JC, ZQW. Resources: JC, ZQW. Supervision: JC, ZQW. Writing the original draft: YYH, JC, ZQW. Writing the review and editing: YYH, JC, ZQW. All authors read and approved the final manuscript.

\section{Funding}

This study was supported by grants from the National Natural Science Foundation of China (U1704284 and 81971952). The funder had no role in the study design, data collection and analysis, decision to publish, or preparation of the manuscript.

\section{Declarations}

\section{Ethics approval and consent to participate}

Ethics approval was acquired from the Institutional Life Science Ethics Committee of Zhengzhou University (No. SCXK 2017-0001). The experimental animals were raised and cared for on the basis of the National Guidelines for Experimental Animal Welfare of the People's Republic of China (2006).

\section{Competing interests}

The authors declare that they have no competing interests.

Received: 17 May 2021 Accepted: 6 July 2021

Published online: 26 August 2021

\section{References}

1. Murrell KD, Pozio E (2011) Worldwide occurrence and impact of human trichinellosis, 1986-2009. Emerg Infect Dis 17:2194-2202

2. Pozio E (2005) The broad spectrum of Trichinella hosts: from cold- to warm-blooded animals. Vet Parasitol 132:3-11

3. Cui J, Jiang P, Liu LN, Wang ZQ (2013) Survey of Trichinella infections in domestic pigs from northern and eastern Henan, China. Vet Parasitol 194:133-135

4. Jiang P, Zhang X, Wang LA, Han LH, Yang M, Duan JY, Sun GG, Qi X, Liu RD, Wang ZQ, Cui J (2016) Survey of Trichinella infection from domestic pigs in the historical endemic areas of Henan province, central China. Parasitol Res 115:4707-4709
5. Rostami A, Gamble HR, Dupouy-Camet J, Khazan H, Bruschi F (2017) Meat sources of infection for outbreaks of human trichinellosis. Food Microbiol 64:65-71

6. Cui J, Wang ZQ, Xu BL (2011) The epidemiology of human trichinellosis in China during 2004-2009. Acta Trop 118:1-5

7. van der Giessen J, Deksne G, Gómez-Morales MA, Troell K, Gomes J, Sotiraki S, Rozycki M, Kucsera I, Djurković-Djaković O, Robertson LJ (2021) Surveillance of foodborne parasitic diseases in Europe in a One Health approach. Parasite Epidemiol Control 13:e00205

8. Liu P, Wang ZQ, Liu RD, Jiang P, Long SR, Liu LN, Zhang XZ, Cheng XC, Yu C, Ren HJ, Cui J (2015) Oral vaccination of mice with Trichinella spiralis nudix hydrolase DNA vaccine delivered by attenuated Salmonella elicited protective immunity. Exp Parasitol 153:29-38

9. Ren HJ, Cui J, Wang ZQ, Liu RD (2011) Normal mouse intestinal epithelial cells as a model for the in vitro invasion of Trichinella spiralis infective larvae. PLoS One 6:e27010

10. Liu RD, Wang ZQ, Wang L, Long SR, Ren HJ, Cui J (2013) Analysis of differentially expressed genes of Trichinella spiralis larvae activated by bile and cultured with intestinal epithelial cells using real-time PCR. Parasitol Res 112:4113-4120

11. Despommier DD (1998) How does Trichinella spiralis make itself at home? Parasitol Today 14:318-323

12. Long SR, Wang ZQ, Jiang P, Liu RD, Qi X, Liu P, Ren HJ, Shi HN, Cui J (2015) Characterization and functional analysis of Trichinella spiralis Nudix hydrolase. Exp Parasitol 159:264-273

13. Wang ZQ, Liu RD, Sun GG, Song YY, Jiang P, Zhang X, Cui J (2017) Proteomic analysis of Trichinella spiralis adult worm excretory-secretory proteins recognized by sera of patients with early trichinellosis. Front Microbiol 8:986

14. Xu J, Yang F, Yang DQ, Jiang P, Liu RD, Zhang X, Cui J, Wang ZQ (2018) Molecular characterization of Trichinella spiralis galectin and its participation in larval invasion of host's intestinal epithelial cells. Vet Res 49:79

15. Hu CX, Zeng J, Yang DQ, Yue X, Liu RD, Long SR, Zhang X, Jiang P, Cui J, Wang ZQ (2020) Binding of elastase-1 and enterocytes facilitates Trichinella spiralis larval intrusion of the host's intestinal epithelium. Acta Trop 211:105592

16. Guo KX, Bai $Y$, Ren HN, Sun $X Y$, Song $Y Y$, Liu RD, Long SR, Zhang $X$, Jiang $P$, Wang ZQ, Cui J (2020) Characterization of a Trichinella spiralis aminopeptidase and its participation in invasion, development and fecundity. Vet Res 51:78

17. Lei JJ, Hu YY, Liu F, Yan SW, Liu RD, Long SR, Jiang P, Cui J, Wang ZQ (2020) Molecular cloning and characterization of a novel peptidase from Trichinella spiralis and protective immunity elicited by the peptidase in BALB/C mice. Vet Res 51:111

18. Wang ZQ, Wang L, Cui J (2012) Proteomic analysis of Trichinella spiralis proteins in intestinal epithelial cells after culture with their larvae by shotgun LC-MS/MS approach. J Proteomics 75:2375-2383

19. Wang L, Wang ZQ, Cui J (2013) Proteomic analysis of the changed proteins of Trichinella spiralis infective larvae after co-culture in vitro with intestinal epithelial cells. Vet Parasitol 194:160-163

20. Ren HN, Liu RD, Song YY, Zhuo TX, Guo KX, Zhang Y, Jiang P, Wang ZQ, Cui J (2019) Label-free quantitative proteomic analysis of molting-related proteins of Trichinella spiralis intestinal infective larvae. Vet Res 50:70

21. Nagano I, Wu Z, Takahashi Y (2009) Functional genes and proteins of Trichinella spp. Parasitol Res 104:197-207

22. Yan SW, Hu YY, Song YY, Ren HN, Shen JM, Liu RD, Long SR, Jiang P, Cui J, Wang ZQ (2020) Characterization of a Trichinella spiralis cathepsin X and its promotion for the larval invasion of mouse intestinal epithelial cells. Vet Parasitol. 109160

23. Qu ZG, Ma XT, Li WH, Zhang NZ, Yue L, Cui JM, Cai JP, Jia WZ, Fu BQ (2015) Molecular characterization of a cathepsin F-like protease in Trichinella spiralis. Parasit Vectors 8:652

24. Han Y, Yue X, Hu CX, Liu F, Liu RD, He MM, Long SR, Cui J, Wang ZQ (2020) Interaction of a Trichinella spiralis cathepsin B with enterocytes promotes the larval intrusion into the cells. Res Vet Sci 130:110-117

25. Li Y, Wang B, Zhu Y, Tian Z, Yang Z, Duan J, Wang Z (2020) The cysteine protease ATG4B of Trichinella spiralis promotes larval invasion into the intestine of the host. Vet Res 51:69

26. Song $Y Y$, Wang LA, Ren HN, Qi X, Sun GG, Liu RD, Jiang P, Zhang X, Cui J, Wang ZQ (2018) Cloning, expression and characterisation of a cysteine protease from Trichinella spiralis. Folia Parasitol 65(2018):007 
27. Cui J, Han Y, Yue X, Liu F, Song YY, Yan SW, Lei JJ, Zhang X, Jiang P, Wang ZQ (2019) Vaccination of mice with a recombinant novel cathepsin B inhibits Trichinella spiralis development, reduces the fecundity and worm burden. Parasit Vectors 12:581

28. Caffrey CR, Goupil L, Rebello KM, Dalton JP, Smith D (2018) Cysteine proteases as digestive enzymes in parasitic helminths. PLoS NegI Trop Dis 12:e0005840

29. Grote A, Caffrey CR, Rebello KM, Smith D, Dalton JP, Lustigman S (2018) Cysteine proteases during larval migration and development of helminths in their final host. PLoS Negl Trop Dis 12:e0005919

30. Liu LN, Wang ZQ, Zhang X, Jiang P, Qi X, Liu RD, Zhang ZF, Cui J (2015) Characterization of Spirometra erinaceieuropaei plerocercoid cysteine protease and potential application for serodiagnosis of sparganosis. PLoS Negl Trop Dis 9:e0003807

31. Sajid M, McKerrow JH (2002) Cysteine proteases of parasitic organisms. Mol Biochem Parasitol 120:1-21

32. Mitreva M, Jasmer DP, Zarlenga DS, Wang Z, Abubucker S, Martin J, Taylor CM, Yin Y, Fulton L, Minx P, Yang SP, Warren WC, Fulton RS, Bhonagiri V, Zhang X, Hallsworth-Pepin K, Clifton SW, McCarter JP, Appleton J, Mardis ER, Wilson RK (2011) The draft genome of the parasitic nematode Trichinella spiralis. Nat Genet 43:228-235

33. Wang ZQ, Li LZ, Jiang P, Liu LN, Cui J (2012) Molecular identification and phylogenetic analysis of Trichinella isolates from different provinces in mainland China. Parasitol Res 110:753-757

34. ManWarren T, Gagliardo L, Geyer J, McVay C, Pearce-Kelling S, Appleton J (1997) Invasion of intestinal epithelia in vitro by the parasitic nematode Trichinella spiralis. Infect Immun 65:4806-4812

35. Jiang $\mathrm{P}$, Wang ZQ, Cui J, Zhang $X$ (2012) Comparison of artificial digestion and Baermann's methods for detection of Trichinella spiralis pre-encapsulated larvae in muscles with low-level infections. Foodborne Pathog Dis 9:27-31

36. Liu RD, Cui J, Liu XL, Jiang P, Sun GG, Zhang X, Long SR, Wang L, Wang ZQ (2015) Comparative proteomic analysis of surface proteins of Trichinella spiralis muscle larvae and intestinal infective larvae. Acta Trop 150:79-86

37. Liu RD, Qi X, Sun GG, Jiang P, Zhang X, Wang LA, Liu XL, Wang ZQ, Cui J (2016) Proteomic analysis of Trichinella spiralis adult worm excretorysecretory proteins recognized by early infection sera. Vet Parasitol 231:43-46

38. Wu Z, Nagano I, Takahashi Y, Maekawa Y (2016) Practical methods for collecting Trichinella parasites and their excretory-secretory products. Parasitol Int 65:591-595

39. Sun GG, Wang ZQ, Liu CY, Jiang P, Liu RD, Wen H, Qi X, Wang L, Cui J (2015) Early serodiagnosis of trichinellosis by ELISA using excretory-secretory antigens of Trichinella spiralis adult worms. Parasit Vectors 8:484

40. Yang W, Li LG, Liu RD, Sun GG, Liu CY, Zhang SB, Jiang P, Zhang X, Ren HJ, Wang ZQ, Cui J (2015) Molecular identification and characterization of Trichinella spiralis proteasome subunit beta type-7. Parasit Vectors 8:18

41. Yue X, Sun XY, Liu F, Hu CX, Bai Y, Yang DQ, Liu RD, Zhang X, Cui J, Wang ZQ (2020) Molecular characterization of a Trichinella spiralis serine proteinase. Vet Res 51:125

42. Cui J, Wang L, Sun GG, Liu LN, Zhang SB, Liu RD, Zhang X, Jiang P, Wang ZQ (2015) Characterization of a Trichinella spiralis $31 \mathrm{kDa}$ protein and its potential application for the serodiagnosis of trichinellosis. Acta Trop 142:57-63

43. Li LG, Wang ZQ, Liu RD, Yang X, Liu LN, Sun GG, Jiang P, Zhang X, Zhang GY, Cui J (2015) Trichinella spiralis: low vaccine potential of glutathione S-transferase against infections in mice. Acta Trop 146:25-32

44. Hu CX, Zeng J, Hao HN, Xu YXY, Liu F, Liu RD, Long SR, Wang ZQ, Cui J (2021) Biological properties and roles of a Trichinella spiralis inorganic pyrophosphatase in molting and developmental process of intestinal larval stages. Vet Res 52:6

45. Sun GG, Ren HN, Liu RD, Song YY, Qi X, Hu CX, Yang F, Jiang P, Zhang X, Wang ZQ, Cui J (2018) Molecular characterization of a putative serine protease from Trichinella spiralis and its elicited immune protection. Vet Res 49:59

46. Liu CY, Song YY, Ren HN, Sun GG, Liu RD, Jiang P, Long SR, Zhang X, Wang ZQ, Cui J (2017) Cloning and expression of a Trichinella spiralis putative glutathione $\mathrm{S}$-transferase and its elicited protective immunity against challenge infections. Parasit Vectors 10:448

47. Xu J, Liu RD, Bai SJ, Hao HN, Yue WW, Xu YXY, Long SR, Cui J, Wang ZQ (2020) Molecular characterization of a Trichinella spiralis aspartic protease and its facilitation role in larval invasion of host intestinal epithelial cells. PLoS Negl Trop Dis 14:e0008269

48. Ren HN, Guo KX, Zhang Y, Sun GG, Liu RD, Jiang P, Zhang X, Wang L, Cui J, Wang ZQ (2018) Molecular characterization of a $31 \mathrm{kDa}$ protein from Trichinella spiralis and its induced immune protection in BALB/c mice. Parasit Vectors 11:625

49. Sun GG, Song YY, Jiang P, Ren HN, Yan SW, Han Y, Liu RD, Zhang X, Wang ZQ, Cui J (2018) Characterization of a Trichinella spiralis putative serine protease. Study of its potential as sero-diagnostic tool. PLoS Negl Trop Dis 12:e0006485

50. Yang Y, Qin W, Tian G, Jian W (2010) Expression and functional characterization of a Rho-family small GTPase CDC42 from Trichinella spiralis. Parasitol Res 107:153-162

51. Li JF, Guo KX, Qi X, Lei JJ, Han Y, Yan SW, Jiang P, Yu C, Cheng XC, Wang ZQ, Cui I (2018) Protective immunity against Trichinella spiralis in mice elicited by oral vaccination with attenuated Salmonella-delivered TsSP1.2 DNA. Vet Res 49:87

52. Qi $X$, Han $Y$, Jiang $P$, Yue $X$, Ren HN, Sun GG, Long SR, Yu C, Cheng XC, Cui J, Wang ZQ (2018) Oral vaccination with Trichinella spiralis DNase II DNA vaccine delivered by attenuated Salmonella induces a protective immunity in BALB/C mice. Vet Res 49:119

53. Liu CY, Ren HN, Song YY, Sun GG, Liu RD, Jiang P, Long SR, Zhang X, Wang ZQ, Cui J (2018) Characterization of a putative glutathione S-transferase of the parasitic nematode Trichinella spiralis. Exp Parasitol 187:59-66

54. Zhang XZ, Sun XY, Bai Y, Song YY, Hu CX, Li X, Cui J, Wang ZQ (2020) Protective immunity in mice vaccinated with a novel elastase-1 significantly decreases Trichinella spiralis fecundity and infection. Vet Res 51:43

55. Cui J, Li LG, Jiang P, Liu RD, Yang X, Liu LN, Liu P, Zhang SB, Wang ZQ (2015) Biochemical and functional characterization of the glutathione S-transferase from Trichinella spiralis. Parasitol Res 114:2007-2013

56. Song YY, Zhang Y, Ren HN, Sun GG, Qi X, Yang F, Jiang P, Zhang X, Cui J, Wang ZQ (2018) Characterization of a serine protease inhibitor from Trichinella spiralis and its participation in larval invasion of host's intestinal epithelial cells. Parasit Vectors 11:499

57. Ren HJ, Liu RD, Wang ZQ, Cui J (2013) Construction and use of a Trichinella spiralis phage display library to identify the interactions between parasite and host enterocytes. Parasitol Res 112:1857-1863

58. Zhang $S B$, Jiang $P$, Wang ZQ, Long SR, Liu RD, Zhang $X$, Yang W, Ren HJ, Cui I (2016) DsRNA-mediated silencing of Nudix hydrolase in Trichinella spiralis inhibits the larval invasion and survival in mice. Exp Parasitol 162:35-42

59. Yang F, Yang DQ, Song YY, Guo KX, Li YL, Long SR, Jiang P, Cui J, Wang ZQ (2019) In vitro silencing of a serine protease inhibitor suppresses Trichinella spiralis invasion, development, and fecundity. Parasitol Res 118:2247-2255

60. Yi N, Yu P, Wu L, Liu Z, Guan J, Liu C, Liu M, Lu Y (2020) RNAi-mediated silencing of Trichinella spiralis serpin-type serine protease inhibitors results in a reduction in larval infectivity. Vet Res 51:139

61. Xu J, Yue WW, Xu YXY, Hao HN, Liu RD, Long SR, Wang ZQ, Cui J (2021) Molecular characterization of a novel aspartyl protease-1 from Trichinella spiralis. Res Vet Sci 134:1-11

62. Sun GG, Lei JJ, Ren HN, Zhang Y, Guo KX, Long SR, Liu RD, Jiang P, Wang ZQ Cui I (2019) Intranasal immunization with recombinant Trichinella spiralis serine protease elicits protective immunity in BALB/C mice. Exp Parasitol 201:1-10

63. Turk B, Turk V, Turk D (1997) Structural and functional aspects of papain-like cysteine proteinases and their protein inhibitors. Biol Chem 378:141-150

64. Keppler D, Sloane BF (1996) Cathepsin B: multiple enzyme forms from a single gene and their relation to cancer. Enzyme Protein 49:94-105

65. Ranjit N, Zhan B, Stenzel DJ, Mulvenna J, Fujiwara R, Hotez PJ, Loukas A (2008) A family of cathepsin B cysteine proteases expressed in the gut of the human hookworm, Necator americanus. Mol Biochem Parasitol 160:90-99

66. Long Y, Cao B, Wang Y, Luo D (2016) Pepsin is a positive regulator of AccathB-2 involved in the rat gut penetration of Angiostrongylus cantonensis. Parasit Vectors 9:286

67. Bien J, Cabaj W, Moskwa B (2015) Proteomic analysis of potential immunoreactive proteins from muscle larvae and adult worms of Trichinella spiralis in experimentally infected pigs. Folia Parasitol 62(2015):022 
68. McVay CS, Bracken P, Gagliardo LF, Appleton J (2000) Antibodies to tyvelose exhibit multiple modes of interference with the epithelial niche of Trichinella spiralis. Infect Immun 68:1912-1918

69. McGonigle L, Mousley A, Marks NJ, Brennan GP, Dalton JP, Spithill TW, Day TA, Maule AG (2008) The silencing of cysteine proteases in Fasciola hepatica newly excysted juveniles using RNA interference reduces gut penetration. Int J Parasitol 38:149-155

70. Zhu B, Luo F, Shen Y, Yang W, Sun C, Wang J, Li J, Mo X, Xu B, Zhang X, Li Y, Hu W (2020) Schistosoma japonicum cathepsin B2 (SjCB2) facilitates parasite invasion through the skin. PLoS Negl Trop Dis 14:e0008810

\section{Publisher's Note}

Springer Nature remains neutral with regard to jurisdictional claims in published maps and institutional affiliations.
Ready to submit your research? Choose BMC and benefit from:

- fast, convenient online submission

- thorough peer review by experienced researchers in your field

- rapid publication on acceptance

- support for research data, including large and complex data types

- gold Open Access which fosters wider collaboration and increased citations

- maximum visibility for your research: over $100 \mathrm{M}$ website views per year

At BMC, research is always in progress.

Learn more biomedcentral.com/submissions 